\title{
Size distribution of particle-bound polychlorinated dibenzo- $p$-dioxins and dibenzofurans in the ambient air of a municipal incinerator
}

\author{
Mu-Rong Chao ${ }^{\mathrm{a}, \mathrm{b}}$, Chiung-Wen $\mathrm{Hu}^{\mathrm{a}}$, Hwong-Wen $\mathrm{Ma}^{\mathrm{c}}$, Gou-Ping Chang-Chien ${ }^{\mathrm{d}}$, \\ Wen-Jhy Lee ${ }^{\mathrm{e}}$, Louis W. Chang ${ }^{\mathrm{a}}$, Kuen-Yuh Wu ${ }^{\mathrm{a}, *}$ \\ ${ }^{a}$ Division of Environmental Health and Occupational Medicine, National Health Research Institutes, 100 Shih-Chuan 1st Road, \\ Kaohsiung 807, Taiwan \\ ${ }^{\mathrm{b}}$ Department of Occupational Safety and Health, Chung Shan Medical University, No. 110, Sec. 1, Chien-Kuo N. Rd., \\ Taichung 402, Taiwan \\ ${ }^{\mathrm{c}}$ Graduate Institute of Environmental Engineering, College of Engineering, National Taiwan University, 71 Chou-Shan Road, \\ Taipei 106, Taiwan \\ ${ }^{\mathrm{d}}$ Department of Chemical Engineering and Super Micro Mass Research and Technology Center, Cheng-Shiu Institute of Technology, \\ 840 Cheng-Ching Road, Kaohsiung 833, Taiwan \\ ${ }^{\mathrm{e}}$ Department of Environmental Engineering, National Cheng Kung University, Tainan 701, Taiwan
}

Received 10 March 2003; received in revised form 29 July 2003; accepted 6 August 2003

\begin{abstract}
The atmospheric particle size distributions of 2,3,7,8-substituted polychlorinated dibenzo- $p$-dioxins and dibenzofurans $(\mathrm{PCDD} / \mathrm{Fs})$ between 0.056 and $100 \mu \mathrm{m}$ in aerodynamic diameter $\left(D_{\mathrm{p}}\right)$ were measured at two sampling sites during January 2002. These sites were 1.1 and $2.1 \mathrm{~km}$ downwind from a municipal incinerator in central Taiwan, respectively. Size-segregated atmospheric particles were simultaneously collected by means of a cascade impactor and a rotary impactor. The results showed that PCDD/Fs were associated with the full size range of atmospheric particles. More than $80 \%$ of the $\Sigma \mathrm{PCDD} / \mathrm{Fs}$ and toxic equivalents (TEQs) were found to be associated with fine particles of aerodynamic diameter, $D_{\mathrm{p}}<2.0 \mu \mathrm{m}$. Generally a smaller particle had a higher $\Sigma \mathrm{PCDD} /$ Fs content. The particle size distributions of $\Sigma \mathrm{PCDD} / \mathrm{Fs}$ and TEQs were shifted to larger particles with increasing time and distance. It is noteworthy that PCDFs were found to distribute significantly among aerosol size fractions based on their chlorination level at both sampling sites. There was an increase in the proportion of the less chlorinated PCDFs in the coarse particles $\left(D_{\mathrm{p}}>2.0 \mu \mathrm{m}\right)$. As for PCDDs, however, a relative enrichment of the less chlorinated congeners on coarse particles was found only at the farther sampling site $(2.1 \mathrm{~km})$.
\end{abstract}

(C) 2003 Elsevier Ltd. All rights reserved.

Keywords: Incinerator; Particle size distribution; PCDD/Fs; Repartitioning

\section{Introduction}

Incineration is the most popular method of municipal solid waste treatment in Taiwan because of its effective-

\footnotetext{
*Corresponding author. Tel.: +886-7-3126772; fax: + 886-7322-1912.

E-mail address: kywu@nhri.org.tw (K.-Y.Wu).
}

ness in reducing the amount and the volume of waste and the possible recovery of exothermic energy (Ma et al., 2002). Incineration of municipal waste is known to emit various atmospheric pollutants including toxic elements and organic compounds. The primary concern on the risks of emissions from incinerators are heavy metals and polychlorinated dibenzo-p-dioxins and dibenzofurans (PCDD/Fs) (Valberg et al., 1996; 
Mukerjee, 1998; National research council (NRC), 2000). At present, municipal solid waste incinerators (MSWIs) are considered to be the major sources of PCDD/Fs emission in many countries (Bolt and Jong, 1993; Coleman et al., 1997; Ogura et al., 2001).

Estimation of potential exposures to $\mathrm{PCDD} / \mathrm{Fs}$ emitted from the stacks of MSWIs requires accurate information on their atmospheric transport, degradation and deposition in the atmosphere. PCDD/Fs are semivolatile organic compounds (SVOCs), which partition between the gas phase and suspended particulate matters in the atmosphere. The partition behavior of SVOCs depends upon the ambient temperature, the relative humidity, the particle surface available for sorption and the compound properties (Lee and Jones, 1999; Lohmann et al., 2000a, b). Since most PCDD/Fs are found in the particulate phase, it becomes important research issue with respect to the particle-bound PCDD/ Fs (Kouimtzis et al., 2002). Gas-phase PCDD/Fs are believed to be depleted due to degradation reactions in the atmosphere, and the particle properties play an important role in the transport of particle-bound PCDD/Fs away from sources (Lohmann and Jones, 1998).

Atmospheric particles are classified into three size groups: ultrafine mode with aerodynamic diameter $<\approx 0.1 \mu \mathrm{m}\left(D_{\mathrm{p}}<0.1 \mu \mathrm{m}\right)$, accumulation mode $(0.1<$ $\left.D_{\mathrm{p}}<2.0 \mu \mathrm{m}\right)$, and coarse size mode $\left(D_{\mathrm{p}}>2.0 \mu \mathrm{m}\right)$ (Bidleman, 1998). Ultrafine mode particles are emitted from combustors and formed in the atmosphere by homogeneous nucleation. Their lifetimes are short (often minutes) due to rapid coagulation forming. Accumulation mode particles also arise from combustion sources and are formed by condensation and coagulation. Coarse mode particles are generated mostly by mechanical processes such as grinding, wind, or erosion.

The transport and deposition of particles can be described as a function of particle size. Therefore, information on the particle size distribution of PCDD/ Fs is essential to estimate their inputs into ecosystems. Additionally, the particle size is important in determining potential impacts on human health, since the efficiencies of both inhalation and reparatory deposition are dependent upon particle size (Oberdorster et al., 1994). Even though a vast number of atmospheric dispersion models exist and are readily available for use, the risk assessor is generally faced with little or no data on the atmospheric particle size distribution of PCDD/ Fs (Lohman and Seigneur, 2001), making accurate risk assessment difficult to conduct.

Studies on PCDD/Fs particle size distribution are few (Kurokawa et al., 1998; Kaupp and McLachlan, 1999; Oh et al., 2002). This was probably because of the long sampling time required to obtain sufficient mass of particles for readily the detection of ultra trace levels of PCDD/Fs. Since sampling of different particle-size fractions was usually performed with cascade impactors, most of the published data were limited to the finer particles $\left(D_{\mathrm{p}}<10 \mu \mathrm{m}\right)$. Larger particles can be separated by rotary impactors (Lee et al., 1996). However, little work has been done to estimate the size distribution of PCDD/Fs within the full size range of atmospheric particles. A recent study by Kaupp and McLachlan (2000) is the only effort in this aspect to describe the complete particle size distribution of $\mathrm{PCDD} / \mathrm{Fs}$ at a rural location. In their study, the atmospheric particles were simply separated into six fractions by the impactors and the resolution was not sufficient for distinguishing minor differences in particle size distributions.

The aim of our present study is to measure the distribution of the 2,3,7,8-substitated PCDD/Fs congeners with respect to particle size in the ambient air of a municipal incinerator. The complete size range of the atmospheric particles was sampled using a micro-orifice uniform deposited impactors (MOUDI) and a Noll Rotary Impactors (NRI). Here the inclusion of MOUDI and NRI allowed collection of particles in 12 size fractions between $<0.056$ and $>100 \mu \mathrm{m}$. Two sites situated downwind of the incinerator were selected to collect ambient air samples simultaneously. Our study represents the first comprehensive investigation for changes of particle size distribution of PCDD/Fs with the distance from the incinerator.

\section{Experimental section}

\subsection{Sampling locations}

The incinerator investigated is in an agricultural zone, located at the slope of a mild hill ( $310 \mathrm{~m}$ high), about $5 \mathrm{~km}$ northwest of Taichung City center. To the west are largely semirural areas and the Taiwan Strait. This incinerator has three rotary furnaces with a nominal capacity rating of 300 ton $\mathrm{day}^{-1}$ each and it employs semidry scrubber and bag filter as air pollution control devices. Finally the fumes are emitted through a $120 \mathrm{~m}$ high stack.

During the winter period, northwest was the prevailing local wind direction. Utilizing historical wind data, two sites (A and B) situated close to the incinerator were selected for the collection of air samples (see Fig. 1). Sites A and B were, respectively, located at about 1.1 and $2.1 \mathrm{~km}$ to the southeast (downwind) of the incinerator. According to our preliminary results for PCDD/Fs and metals collected by high volume air samplers around the incinerator (carried out with the present study in parallel), the air pollutant concentrations at these two sites were found to be highly influenced by the air dispersion downstream of the incinerator (Chao et al., 2003; Hu et al., 2003). It would be assumed that the two sampling sites represented 


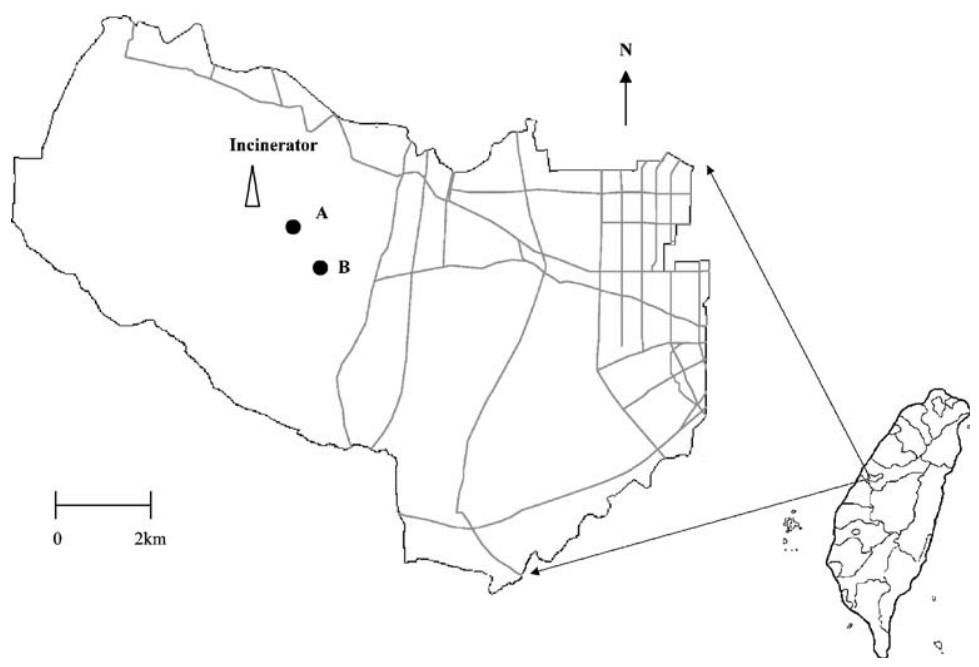

Fig. 1. Map of the sampling locations.

consecutive measurements of the same air mass from the incinerator.

\subsection{Air sampling}

Atmospheric particles in each site were simultaneously collected by the MOUDIs (Model 110 MSP Co., Minneapolis, MN) and the NRIs. The sampling apparatus was calibrated with the unit density spherical particles so that all particles collected are sized aerodynamically equivalent to the reference particles. Then the complete particle size distributions from 0.056 to $100 \mathrm{~mm}$ could be obtained for particle-bound PCDD/ Fs analyses.

The MOUDI is a ten-stage cascade impactor, which was used to provide resolution of the size distribution of aerosol population including finer particles. The sampling method employed has been described elsewhere (Sheu et al., 1997). Briefly, 47-mm aluminum foils (MSP Co.) and a 37-mm Zefluor filter (Gelman Sciences Co., $2 \mathrm{~mm}$ pore) were, respectively, used as the impaction substrates and backup filter for the MOUDI sampler. Both aluminum foils and Zeflour filters were prewashed with a solvent solution (mixture of $n$-hexane and dichloromethane, $v: v=1: 1)$ for $24 \mathrm{~h}$. In order to reduce particle bounce during sampling, the aluminum foils were coated with $2 \mathrm{mg}$ of silicon grease (thickness $\approx 1 \mu \mathrm{m}$ ) to form a sticky surface (Sheu et al., 1997). All coated aluminum foils were then treated at $60^{\circ} \mathrm{C}$ for $90 \mathrm{~min}$ to obtain smooth and even surfaces. These aluminum foils and filters were weighed before and after sampling to determine the amount of particle collected for each stage. In this study, the aluminum foils and filters of the MOUDI were changed every $24 \mathrm{~h}$. At a flow rate of $301 \mathrm{~min}^{-1}$, the $50 \%$ cut off diameter $\left(D_{50}\right)$ were
$0.056,0.1,0.18,0.32,0.56,1.0,1.8,3.2,5.6,10$, and $18 \mu \mathrm{m}$ (Marple et al., 1991).

The NRI is a multistage rotary inertial impactor that collects coarse particles by rotating four rectangular collectors (stages) of different dimensions through the air. More detailed informations on the NRI were described in elsewhere (Noll et al., 1985, 1990). The stages were covered with Mylar strips coated with silicon grease. Total collection areas were 1.2, 3.1, 10.3 and $10.3 \mathrm{~cm}^{2}$ for the four stages of NRI, respectively. The strips were weighed before and after sampling to determine the particle mass collected. For this study, the NRI was operated at $320 \mathrm{rpm}$ as described by Lee et al. (1996). The NRI was operated for a maximum of $12 \mathrm{~h}$ before the Mylar strips were replaced. The theoretical aerodynamic cut-diameters range (assuming a particle density of $1 \mathrm{~g} \mathrm{~cm}^{-3}$ ) for the four stages were $6.5-100,11.5-100,24.7-100$ and $36.5-100 \mathrm{~mm}$, respectively.

Accordingly, the concentration at overlap size ranges measured by both MOUDI (5.6-10 and 10-18 $\mu \mathrm{m})$ and NRI $(6.5-11.5$ and $11.5-24.7 \mu \mathrm{m})$ was presented by the averaged data. After combining the MOUDI and NRI, the normalized particle size range for each stage, in sequence, is $0.056-0.1,0.1-0.18,0.18-0.32,0.32-0.56$, $0.56-1.0,1.0-1.8,1.8-3.2,3.2-5.6,5.6-10,10-24.7,24.7-$ 36.5 and $36.5-100 \mu \mathrm{m}$ (Sheu et al., 1997).

Sampling was performed continuously in the winter (8-29 January) of 2002 during dry periods with uniform weather conditions. A total of 21 particle size samples were collected at each sampling site. During the sampling days, the metrological data were obtained from a nearby metrological station. On a weekly basis, temperature, wind speed and direction, and relative humidity are described in Table 1 . Notably, the major 
Table 1

Environmental conditions during the sampling campaign

\begin{tabular}{lllll}
\hline Sampling period & Mean temp $\left({ }^{\circ} \mathrm{C}\right)$ & Prevailing wind direction $(\%)$ & Mean wind speed $\left(\mathrm{m} \mathrm{s}^{-1}\right)$ & Mean relative humidity $(\%)$ \\
\hline $1 / 8-1 / 15$ & 18.5 & $\mathrm{~N}(50), \mathrm{NW}(38), \mathrm{SW}(12)$ & 2.3 & 74.6 \\
$1 / 15-1 / 22$ & 18.5 & $\mathrm{~N}(13), \mathrm{NW}(63), \mathrm{SW}(12)$ & 3.8 & 75.1 \\
$1 / 22-1 / 29$ & 14.7 & $\mathrm{NW}(100)$ & 4.2 & 75.6 \\
\hline
\end{tabular}

wind direction was from the northwest with a speed allowing a good dispersion. Once the sampling was completed, the samples were immediately stored in a freezer at $-20^{\circ} \mathrm{C}$ and were analyzed within 4 weeks. Due to the extremely low substance concentrations on separate particle fractions, the corresponding particle fractions over a 21-day period were combined for analysis.

\subsection{Analytical procedure}

Analysis of seventeen 2,3,7,8-substituted PCDD/Fs congeners in aerosol samples was performed by the Super MicroMass Research and Technology Center in Cheng-Shiu Institute of Technology. This center is the only accredited laboratory in Taiwan for PCDD/Fs analysis and passes the international intercalibration on PCDD/Fs in environmental and human samples. The extraction and clean-up procedures, as well as the analytical determination of $\mathrm{PCDD} / \mathrm{Fs}$ were carried out as recently reported (Wang et al., 2003a). All PCDD/Fs standards in this study were obtained from Wellington Laboratories Inc. (Wellington, CT); solvents and reagents were pesticide grade/high purity.

The PCDD/Fs were analyzed by high-resolution gas chromatography/high-resolution mass spectrometry (HRGC/HRMS) using an HP5890 gas chromatography connected to a Micromass AutoSpec-Ultima mass spectrometry at a resolving power of 10,000. A DB-5 MS column (J\&W, length $60 \mathrm{~m}$, i.d. $0.25 \mathrm{~mm}$, film thickness $0.25 \mu \mathrm{m}$, carrier gas helium) was employed with the following temperature program: initial $150^{\circ} \mathrm{C}$ (1 $\mathrm{min}), 30^{\circ} \mathrm{C} \mathrm{min}^{-1}$ to $220^{\circ} \mathrm{C}(12 \mathrm{~min}), 1.5^{\circ} \mathrm{C} \mathrm{min}^{-1}$ to $240^{\circ} \mathrm{C}(5 \mathrm{~min}), 15^{\circ} \mathrm{C} \mathrm{min}^{-1}$ to $310^{\circ} \mathrm{C}(20 \mathrm{~min})$. Two masses were recorded for each analyte and each isotopelabeled standard. Quantitation of analytes was achieved by using the isotope dilution relative internal standard method referring to the peak areas of the specific ${ }^{13} \mathrm{C}_{12}$ labeled surrogate for each 2,3,7,8-PCDD/F analyte. Field and laboratory blanks samples were routinely analyzed for quality assurance purposes. Blank levels were normally very low and in most cases not detectable. The levels for individual isomers often had to be based on background noise and the instrumental detection limit. Recoveries of ${ }^{13} \mathrm{C}_{12}$-labeled PCDD/Fs internal standards in environmental samples ranged between $75 \%$ and $107 \%$. Method detection limits were $0.8 \mathrm{fg} \mathrm{m}^{-3}$ for OCDD and $<0.3 \mathrm{fg} \mathrm{m}^{-3}$ for other congeners.

\section{Results and discussion}

\subsection{Concentrations of PCDD/Fs with particle size}

The concentrations $\left(\mathrm{pg} \mathrm{m}^{-3}\right)$ of individual 2,3,7,8substituted $\mathrm{PCDD} / \mathrm{F}$ congeners determined in the different particle size ranges for sites $\mathrm{A}$ and $\mathrm{B}$, respectively, are summarized in Table 2 . PCDD/Fs were found to be associated with the full size range of atmospheric particles. The concentrations of higher chlorinated congeners $(\mathrm{HpCDD} / \mathrm{F}$ and $\mathrm{OCDD} / \mathrm{F})$ were remarkably higher than those of other less chlorinated congeners. It is known that a considerable fraction of less chlorinated $\mathrm{PCDD} / \mathrm{Fs}$ is present in the gas phase under normal ambient temperature (Lee and Jones, 1999; Kouimtzis et al., 2002). Kaupp et al. (1994) reported tetra-CDD, penta-CDD and tetra-CDF were frequently below the detection limits for all size ranges. In our study, while the corresponding particle fractions over a 21-day sampling time were combined to obtain a sufficient mass of particles to readily detect the PCDD/ Fs, only 2,3,7,8-TeCDD and 1,2,3,7,8-PeCDD were not found on parts of size ranges. OCDD was the most prominent congener for the full size range of atmospheric particles. It has been reported that OCDD usually dominated the congeners profile in stack emissions of MSWIs (Lorber et al., 1998; Wang et al., 2003b). This finding reflected that PCDD/Fs concentrations could be highly influenced by the incinerator emissions. When comparing the total particle-bound $\mathrm{PCDD} / \mathrm{Fs}$ and the total toxic equivalents (TEQs) over the full size range for sites $\mathrm{A}$ and $\mathrm{B}$, slight decreases were observed with increasing distance from the incinerator. As a result of atmospheric dilution, the total particle-bound PCDD/Fs decreased from 2929 to $2539 \mathrm{fg} \mathrm{m}^{-3}$ and the total TEQs decreased from 75.4 to $69.4 \mathrm{fg}$ I-TEQ $\mathrm{m}^{-3}$.

\subsection{Particle size distributions of $\Sigma P C D D / F$ s and TEQs}

The normalized distributions of the $\Sigma \mathrm{PCDD} / \mathrm{Fs}$ with particle size are presented in Fig. 2. The major peaks are located in the accumulation mode size range, 
Table 2

Concentrations of 2,3,7,8-substitated $\mathrm{PCDD} /$ Fs congeners with respect to particle size at the sites A and $\mathrm{B}$

\begin{tabular}{|c|c|c|c|c|c|c|c|c|c|c|}
\hline \multirow[t]{3}{*}{ Compound ( $\mathrm{fg} \mathrm{m}^{-3}$ ) } & \multicolumn{10}{|c|}{ Aerodynamic diameter, $D_{\mathrm{p}}(\mu \mathrm{m})$} \\
\hline & \multicolumn{5}{|l|}{ Site A } & \multicolumn{5}{|l|}{ Site B } \\
\hline & $0.056-0.32$ & $0.32-1.8$ & $1.8-10$ & $10-100$ & Total & $0.056-0.32$ & $0.32-1.8$ & $1.8-10$ & $10-100$ & Total \\
\hline 2,3,7,8-TeCDD & n.d. ${ }^{\mathrm{a}}$ & 0.85 & n.d. & 0.12 & 0.97 & 0.89 & n.d. & n.d. & 0.08 & 0.98 \\
\hline $1,2,3,7,8-\mathrm{PeCDD}$ & 1.66 & 4.77 & 1.41 & n.d. & 7.84 & 4.14 & 4.91 & 2.33 & 0.65 & 12.0 \\
\hline 1,2,3,4,7,8-HxCDD & 8.21 & 8.45 & 2.74 & 0.71 & 20.1 & 7.07 & 9.12 & 2.42 & 0.65 & 19.3 \\
\hline 1,2,3,6,7,8-HxCDD & 15.4 & 13.5 & 4.36 & 1.14 & 34.4 & 12.2 & 14.4 & 3.40 & 0.97 & 31.0 \\
\hline $1,2,3,7,8,9-\mathrm{HxCDD}$ & 13.4 & 12.7 & 3.35 & 0.90 & 30.3 & 11.0 & 12.8 & 3.50 & 0.97 & 28.3 \\
\hline 1,2,3,4,6,7,8-HpCDD & 113 & 136 & 34.1 & 6.99 & 290 & 86.8 & 145 & 24.8 & 6.75 & 263 \\
\hline OCDD & 410 & 788 & 308 & 37.6 & 1544 & 279 & 926 & 166 & 36.1 & 1408 \\
\hline $2,3,7,8-\mathrm{TeCDF}$ & 4.28 & 4.42 & 4.09 & 1.42 & 14.2 & 3.27 & 3.82 & 3.47 & 1.56 & 12.1 \\
\hline $1,2,3,7,8-\mathrm{PeCDF}$ & 10.8 & 11.1 & 7.64 & 2.46 & 32.0 & 8.55 & 11.1 & 6.56 & 2.62 & 28.9 \\
\hline $2,3,4,7,8-\mathrm{PeCDF}$ & 20.7 & 19.2 & 10.1 & 3.11 & 53.0 & 15.7 & 19.5 & 8.53 & 2.98 & 46.7 \\
\hline $1,2,3,4,7,8-\mathrm{HxCDF}$ & 32.6 & 29.6 & 10.6 & 2.81 & 75.7 & 24.4 & 30.8 & 8.49 & 2.96 & 66.6 \\
\hline 1,2,3,6,7,8-HxCDF & 30.2 & 25.6 & 9.19 & 2.52 & 67.5 & 22.8 & 27.3 & 7.03 & 2.77 & 59.8 \\
\hline $2,3,4,6,7,8-\mathrm{HxCDF}$ & 44.1 & 33.7 & 9.45 & 2.50 & 89.8 & 32.9 & 34.8 & 6.89 & 2.67 & 77.3 \\
\hline 1,2,3,7,8,9-HxCDF & 4.84 & 4.24 & 1.89 & 0.46 & 11.4 & 3.70 & 4.13 & 2.54 & 0.59 & 11.0 \\
\hline $1,2,3,4,6,7,8-\mathrm{HpCDF}$ & 136 & 117 & 25.3 & 7.52 & 286 & 100 & 117 & 19.3 & 8.09 & 245 \\
\hline $1,2,3,4,7,8,9-\mathrm{HpCDF}$ & 23.2 & 19.8 & 4.12 & 1.18 & 48.3 & 17.2 & 19.6 & 3.44 & 1.43 & 41.6 \\
\hline OCDF & 193 & 102 & 21.0 & 8.05 & 324 & 73.9 & 90.3 & 16.2 & 7.97 & 188 \\
\hline$\Sigma \mathrm{PCDD} / \mathrm{Fs}^{\mathrm{b}}$ & 1062 & 1331 & 456 & 79.5 & 2929 & 704 & 1471 & 285 & 79.7 & 2539 \\
\hline TEQs (fg I-TEQ $\left.\mathrm{m}^{-3}\right)^{\mathrm{c}}$ & 30.3 & 30.2 & 11.7 & 3.25 & 75.4 & 25.3 & 30.3 & 10.2 & 3.55 & 69.4 \\
\hline Particle mass $\left(\mu \mathrm{g} \mathrm{m}^{-3}\right)$ & 33.1 & 69.1 & 47.0 & 17.7 & 167.0 & 24.4 & 62.0 & 24.4 & 25.1 & 135.8 \\
\hline
\end{tabular}

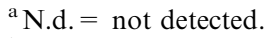

${ }^{\mathrm{b}} \Sigma \mathrm{PCDD} / \mathrm{Fs}$ were calculated as sum of tera- to octa-chlorinated 2,3,7,8-substitated PCDD/Fs.

${ }^{\mathrm{c}}$ TEQs were calculated using I-TEF (international toxic equivalent factors).

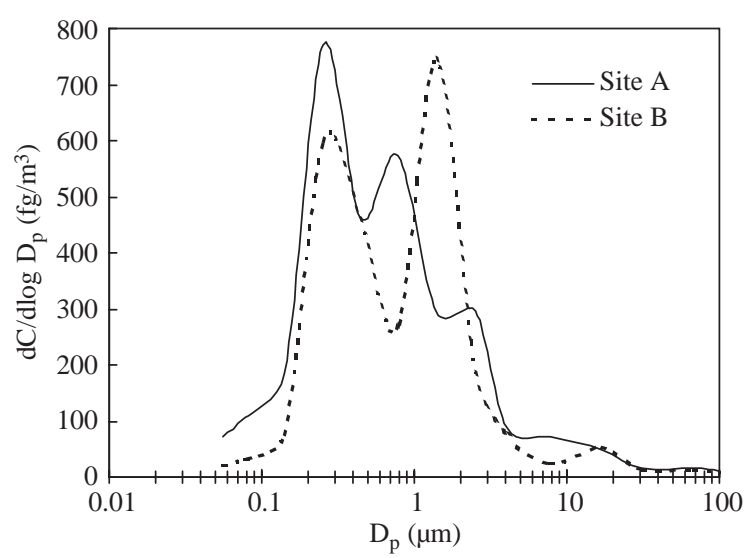

Fig. 2. Particle size distributions of $\Sigma \mathrm{PCDD} / \mathrm{Fs}$.

$0.1<D_{\mathrm{p}}<2.0 \mu \mathrm{m}$. It is generally accepted that PCDD/Fs associated with small particles tend to result from combustion (Lohmann and Jones, 1998). Our data further implied that the PCDD/Fs collected at sites A and $\mathrm{B}$ could mainly originate from the incinerator emission. The shift in the particle size distribution of $\Sigma \mathrm{PCDD} / \mathrm{Fs}$ from site $\mathrm{A}$ to $\mathrm{B}$ was observed. This discrepancy between sites A and B was successfully revealed by the high particle size resolution of our impactors. For site A, the $\Sigma \mathrm{PCDD} / \mathrm{Fs}$ were distributed in analogously trimodal distributions with a major peak at $D_{\mathrm{p}} \approx 0.25 \mu \mathrm{m}$ and two additional minor peaks at $D_{\mathrm{p}} \approx 0.78$ and $\approx 2.5 \mu \mathrm{m}$. At site $\mathrm{B}$, the particle size distribution of $\Sigma \mathrm{PCDD} /$ Fs was clearly bimodal within the accumulation mode size range. The first peak was located at $D_{\mathrm{p}} \approx 0.25 \mu \mathrm{m}$ and the second peak was located at $D_{\mathrm{p}} \approx 1.4 \mu \mathrm{m}$. An addition minor peak in the coarse mode size range at $D_{\mathrm{p}} \approx 17 \mu \mathrm{m}$ was also noted. From site A to B, the distribution of $\Sigma \mathrm{PCDD} / \mathrm{Fs}$ was shifted to larger particles. This could be due to the fact that the newly released particles from the incinerator had not reached equilibrium in the ambient air at short distance. $\mathrm{PCDD} / \mathrm{Fs}$ emitted were initially released in the gas phase and were primarily associated with fine particles. Then, $\mathrm{PCDD} /$ Fs can migrate to larger particles by coagulation or by vaporization and sorption processes with increasing time and distance (from site A to B). Our study also demonstrates that the major peaks for TEQs were in the accumulation mode size range (data not shown), similar to the distributions observed for $\Sigma \mathrm{PCDD} / \mathrm{Fs}$.

However, it should be mentioned that only two sets of samples were analyzed in this study and there might be some uncertainty in our measurements. Moreover, sizesegregated atmospheric aerosols were collected on light greased impaction media in this work to prevent particle 
bounce during sampling. It has been suspected that the use of greased impaction media may have led to absorption of $\mathrm{PCDD} / \mathrm{Fs}$ present in the gas phase (Kaupp and McLachlan, 2000). Such absorption would artificially increase the amount of $\mathrm{PCDD} / \mathrm{Fs}$ attributed to the aerosol and possibly distort the measured size distributions. Nevertheless, the PCDD/Fs had distributions with distinct peaks in this study (see Fig. 2). This might imply that the absorption artifact only result in a small increase in the amount of PCDD/Fs collected and no qualitatively significant distortion in the measured distributions (Allen, 1997).

\subsection{Cumulative percentage of particle size distribution}

Information on the cumulative percentage of the particle size distribution is useful for the comparison of the contributions of fine and coarse particles to the $\mathrm{PCDD} / \mathrm{Fs}$ concentrations. In this study, the sum of ultrafine $\left(D_{\mathrm{p}}<0.1 \mu \mathrm{m}\right)$ and accumulation $(0.1<$ $\left.D_{\mathrm{p}}<2.0 \mu \mathrm{m}\right)$ fractions was considered as the fine fraction $\left(D_{\mathrm{p}}<2.0 \mu \mathrm{m}\right)$. The fine and coarse particle fractions were differentiated at $2.0 \mu \mathrm{m}$. Our investigation revealed that the cumulative percentages of the $\Sigma \mathrm{PCDD} / \mathrm{Fs}$ mass for particle size $<2.0 \mu \mathrm{m}$ were $83.9 \%$ and $87.3 \%$ for sites A and $\mathrm{B}$, respectively. Furthermore, more than $80 \%$ of the TEQs were found to be present in the fine particle fraction for both sites A and B. Our findings on the dominant contribution of the fine particles to the $\mathrm{PCDD} / \mathrm{Fs}$ in this study were consistent with those reported by Kurokawa et al. (1998) and by Kaupp and McLachlan (1999). Because the fine particles have a lower dry deposition velocity, the PCDD/Fs associated primarily with the fine particles tend to be transported from the incinerator for a long distance. This would help to explain the observation by Lorber et al. (1998), who indicated that $<2 \%$ of emitted $\mathrm{PCDD} / \mathrm{Fs}$ could be found in the soil close to the incinerator. These fine particles are believed to be dispersed to an extensive area, being easily respired into the deep portions of the lungs where the $\mathrm{PCDD} / \mathrm{Fs}$ may produce a greater danger to health.

\subsection{Comparison of PCDDs and PCDFs}

The ratio of $\Sigma$ PCDDs/ $\Sigma$ PCDFs was previously reported to be a good indicator for possible formation processes or emission sources of the PCDD/Fs (Lee et al., 1999; Lohmann et al., 1999; Schnelle-Kreis et al., 2001). As illustrated in Fig. 3, the $\Sigma$ PCDDs/ $\Sigma$ PCDFs ratio distributions with respect to particle size were quite similar for sites A and B. Except for particles with $D_{\mathrm{p}}<0.2 \mu \mathrm{m}$, the PCDDs levels were higher than PCDFs. The ratio of $\Sigma$ PCDDs/ $\Sigma$ PCDFs varied from 0.58 to 5.6 over the full size range, with mean values of 1.9 and 2.3 for sites A and B, respectively. It was reported that the

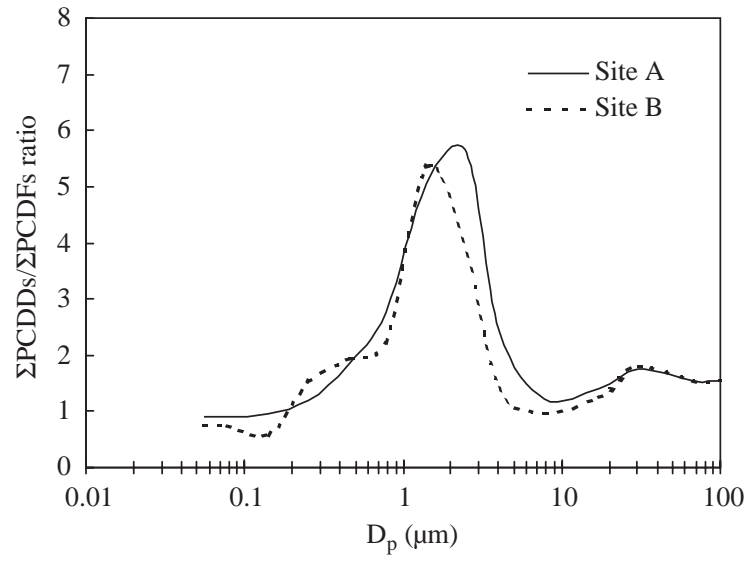

Fig. 3. Distributions of $\Sigma$ PCDDs/ $/ \mathrm{PCDF}$ s ratio with particle size.
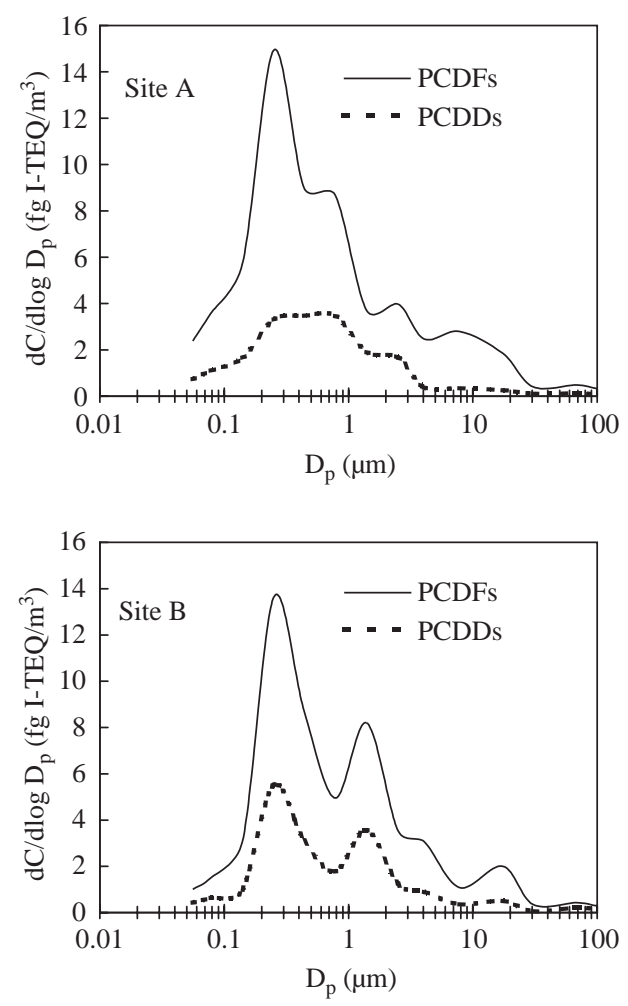

Fig. 4. Distributions of TEQs for PCDDs and PCDFs with particle size.

$\Sigma$ PCDDs/ $\Sigma$ PCDFs ratio of fly ashes collected from the MSWIs in Taiwan were frequently higher than 1 (Chang and Huang, 1999). Therefore, it was reasonable to assume that the PCDD/Fs found in the fly ashes and atmospheric particles were both caused by similar formation processes (i.e. incinerator combustion). 
The distributions of TEQs for PCDDs and for PCDFs with particle size are shown in Fig. 4. The TEQs for PCDDs were distributed differently from those for PCDFs at site A. However, the distributions of TEQs for PCDDs and PCDFs at site B were very similar. In contrast to the observation from the $\Sigma$ PCDDs/ $\Sigma$ PCDFs ratio, the TEQs for PCDFs were 2-8 times higher than those for PCDDs over the full particle size range. In our study, PCDFs were the major contributors to the TEQs in the atmospheric particles at the downwind sites of the incinerator. This is in agreement with previous data reported for particle-bound PCDD/Fs (Kurokawa et al., 1998; Kouimtzis et al., 2002).

\subsection{Size distribution of individual homologue}

The distributions of 2,3,7,8-substituted PCDD/Fs homologues with respect to particle size expressed as percent of the total particle-bound concentration of each homologue are shown in Fig. 5. Clearly, the PCDFs tend to be distributed with particle size based on molecular weight; higher chlorinated congeners with fine particles and lower chlorinated congeners with coarse particles (see Figs. 5a and b). At $D_{\mathrm{p}}>2.0 \mu \mathrm{m}$, the
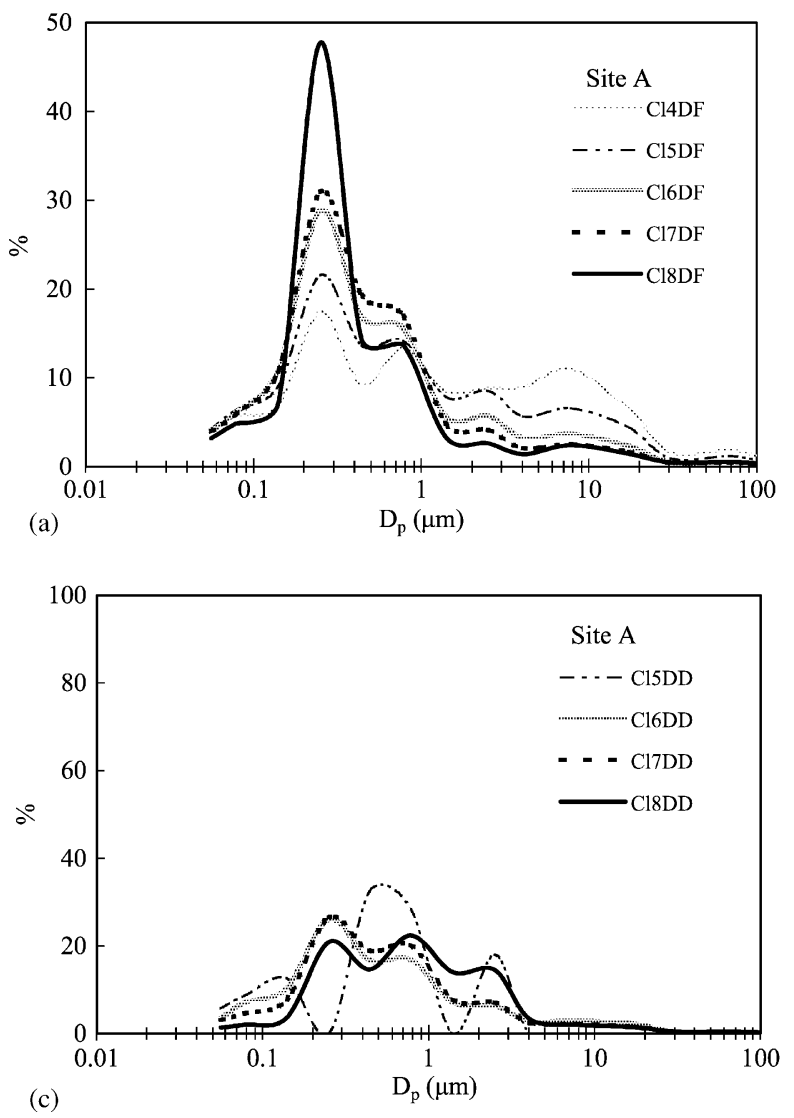

Fig. 5. Percent particle size distribution of individual 2,3,7,8-substituated congeners.

(d) percent concentrations of PCDFs for site A were in the order of TeCDF $(29 \%)>\mathrm{PeCDF} \quad(18 \%)>\mathrm{HxCDF}$ $(10 \%)>\operatorname{HpCDF}(7 \%)>\mathrm{OCDF}(6 \%)$. Moreover, the PCDFs concentrations of site B had similar pattern as those in site A.

PCDD/Fs and PAHs are both SVOCs formed as byproducts of combustion. Analogies to PAHs and their redistribution mechanisms may explain likely $\mathrm{PCDD} / \mathrm{Fs}$ behavior. Several studies on PAHs have also shown that higher molecular weight PAHs were sorbed to the fine aerosol fraction, but more volatile PAHs were associated with larger particles (Allen et al., 1998; Offenberg and Baker, 1999). Allen et al. (1996) indicated that the mass transfer of PAHs from fine to coarse particles by volatilization and sorption was directly related to the fraction of PAHs in the gas phase relative to that in the particle phase. The rates of redistribution for PAHs correlate with their subcooled liquid vapor pressures. In addition, differences in chemical affinities between PAHs and different size particles have also been used to explain the observed PAHs distribution pattern with respect to particle size (Venkataraman et al., 1999).

PCDD/Fs vapor pressures have been demonstrated to be strongly correlated with levels of chlorination
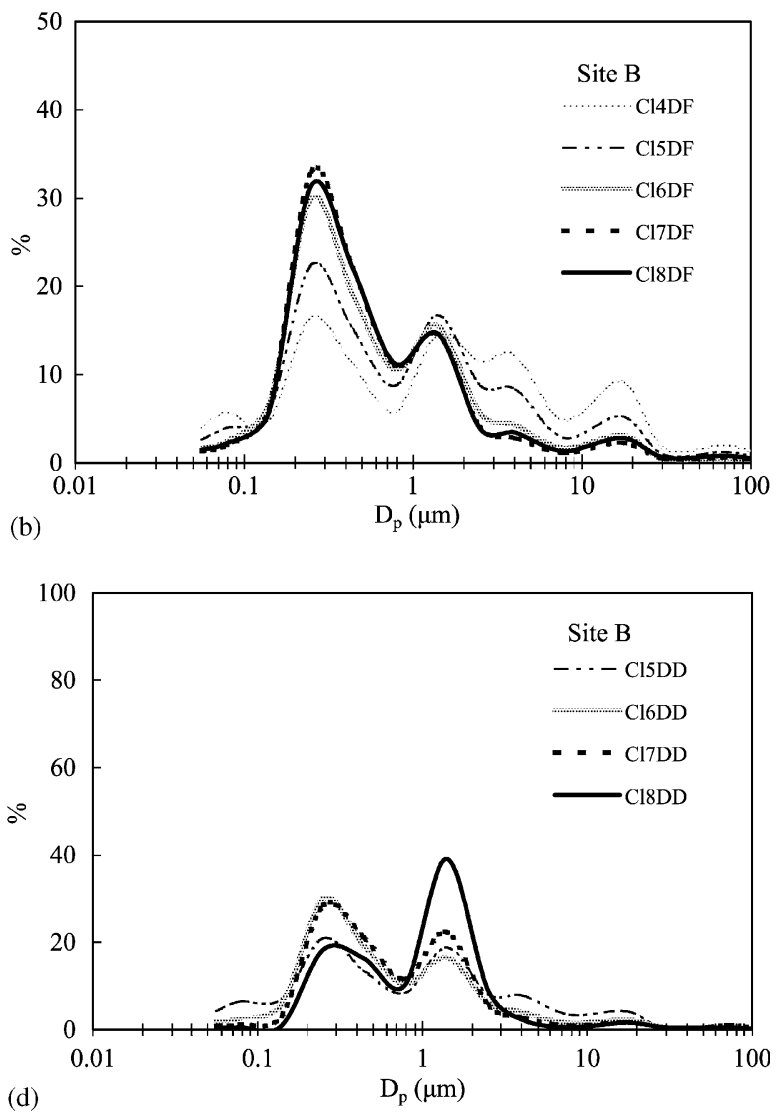
(Oh et al., 2001). One possible explanation for the observed $\mathrm{PCDD} /$ Fs distribution pattern is that PCDD/ Fs were initially associated with fine particles following emission by the incinerator and then PCDD/Fs could become associated coarse particles $\left(D_{\mathrm{p}}>2.0 \mu \mathrm{m}\right)$ either by coagulation or by vaporization and sorption. If the main mechanism for PCDD/Fs associated with coarse particles was only the coagulation of particles, the mixture of $\mathrm{PCDD} / \mathrm{Fs}$ in fine and coarse particles would be similar. However, Fig. 5 demonstrated that this was not observed. Instead, a redistribution of the more volatile $\mathrm{PCDD} / \mathrm{Fs}$ could occur, with the less chlorinated $\mathrm{PCDD} / \mathrm{Fs}$ volatilizing more rapidly from the fine particles and sorbing to the coarse particles than the higher chlorinated $\mathrm{PCDD} / \mathrm{Fs}$. The relative amounts of PCDD/Fs bound to the fine particles can therefore increase with increasing chlorination level, which is in accordance with previous studies (Kaupp et al., 1994; Oh et al., 2002). Moreover, it should be mentioned that differences in chemical affinities between PCDD/Fs and different size particles could also explain the observed PCDD/Fs distribution pattern in this study.

As for the PCDDs, the distribution of TeCDD and PeCDD showed a high variability (data not shown). This may be due to the difficulty of working close to the detection limits for these less chlorinated congeners. In contrast to the findings of PCDFs, the PCDDs distributions give less implication of a relative enrichment of the higher chlorinated congeners on finer particles (see Figs. 5c and d). One of the reasons for the irregular distribution of PCDDs is that PCDDs generally have lower vapor pressures than equivalent PCDF homologue groups (Lee and Jones, 1999), giving further hints that PCDDs could redistribute to larger particles by vaporization and sorption more difficultly than PCDFs. However, at the farther site B, the PCDDs still appeared to distribute among the aerosol size fractions based on chlorination level. Except for TeCDD, the percent concentrations of PCDDs found on coarse particles $\left(D_{\mathrm{p}}>2.0 \mu \mathrm{m}\right)$ were in the order of $\mathrm{PeCDD}(16 \%)>\mathrm{HxCDD}(8 \%)>\operatorname{HpCDD}(6 \%)>$ OCDD $(5 \%)$ at site B. Less chlorinated PCDD/Fs are more associated with coarse particles, which have substantial deposition velocities. These PCDD/Fs are expected to have a larger flux out of atmosphere by deposition.

Only a very small part of PCDD/Fs were associated with particle size greater than $30 \mu \mathrm{m}$ for both sites A and B. These large particles were originally little contaminated with $\mathrm{PCDD} / \mathrm{Fs}$ due to their occurrence from nonthermal sources. In addition, the atmospheric residence times of large particles $\left(D_{\mathrm{p}}>30 \mu \mathrm{m}\right)$ are short and, therefore, the time available for the sorption by the atmospheric gas phase PCDD/Fs is limited (Kaupp and McLachlan, 2000).

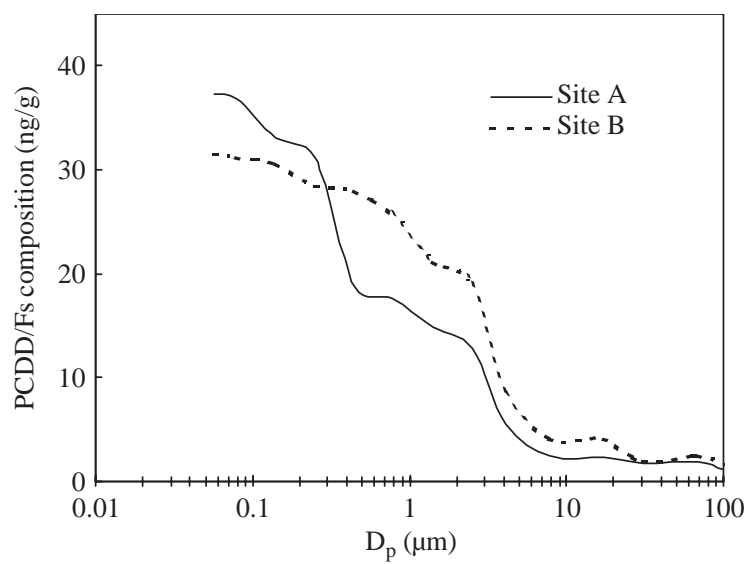

Fig. 6. Particle size distributions of particle-bound $\Sigma$ PCDD/Fs content $\left(\mathrm{ng} \mathrm{g}^{-1}\right)$.

\section{6. $\Sigma P C D D / F s$ content on particles}

The particle size distributions of the $\Sigma \mathrm{PCDD} / \mathrm{Fs}$ are expressed as nanograms of substance per gram of particles $\left(\mathrm{ng} \mathrm{g}^{-1}\right)$ in Fig. 6. In general, a smaller particle has a higher $\Sigma \mathrm{PCDD} / \mathrm{Fs}$ content. The major peak in particle size distribution for $\Sigma \mathrm{PCDD} / \mathrm{Fs}$ content was found in a particle size range between 0.056 and $3 \mu \mathrm{m}$. This is due to the fact that soot emitted from the incinerator might be primarily made up of fine particles, which carry a high content of $\mathrm{PCDD} / \mathrm{Fs}$. At $D_{\mathrm{p}}<0.25 \mu \mathrm{m}$, the $\Sigma \mathrm{PCDD} / \mathrm{Fs}$ content for site A was higher than that for site $\mathrm{B}$, whereas the opposite result was observed on particles with $D_{\mathrm{p}}>0.25 \mu \mathrm{m}$. PCDD $/ \mathrm{Fs}$ associated with particles $<0.25 \mu \mathrm{m}$ appear to shift toward larger particles. Again, this finding further demonstrated that, once associated with fine particles, PCDD/Fs could migrate to larger particles by vaporization and sorption or by coagulation. The measured particle-bound $\mathrm{PCDD} /$ Fs content is useful when examining the deposition flux of $\mathrm{PCDD} / \mathrm{Fs}$ to receptors or their transfer from deposited particles to the receptor surface (Kaupp and McLachlan, 1999).

Particle size affects the removal rate of $\mathrm{PCDD} / \mathrm{Fs}$ from the atmosphere by dry and wet deposition. Consequently, this study provides further elucidation on the $\mathrm{PCDD} / \mathrm{Fs}$ mass transfer from fine to coarse particles. This information is also helpful in understanding the environmental fate of $\mathrm{PCDD} / \mathrm{Fs}$ in the atmosphere.

\section{Acknowledgements}

This research was supported by funds from the National Health Research Institutes, Taiwan, Grant No. EO-090100017. The scientific content of this 
manuscript has been reviewed and approved for publication by the Division of Environmental Health and Occupational Medicine of the National Health Research Institutes. Approval for publication does not necessarily signify that the content reflects the view and policies of the DEHOM/NHRI, or condemnation or endorsement and recommendation for use on this issue presented.

\section{References}

Allen, J.O., 1997. Atmospheric Partitioning of Polycyclic Aromatic Hydrocarbons (PAHs) and Oxygenated PAH. Sc.D. Thesis, M.I.T., Cambridge, MA.

Allen, J.O., Dookeran, K.M., Smith, K.A., Sarofim, A.F., Taghizadeh, K., Lafleur, A.L., 1996. Measurement of polycyclic aromatic hydrocarbons associated with sizesegregated atmospheric aerosols in Massachusetts. Environmental Science and Technology 30, 1023-1031.

Allen, J.O., Durant, J.L., Dookeran, N.M., Taghizadeh, K., Plummer, E.F., Lafleur, A.L., Sarofim, A.F., Smith, K.A., 1998. Measurement of $\mathrm{C}_{24} \mathrm{H}_{14}$ polycyclic aromatic hydrocarbons associated with a size-segregated urban aerosol. Environmental Science and Technology 32, 1928-1932.

Bidleman, T.F., 1998. Atmospheric process. Environmental Science and Technology 22, 361-367.

Bolt, A., Jong, A.P.J.M., 1993. Ambient air dioxin measurement in the Netherlands. Chemosphere 27, 73-81.

Chang, M.B., Huang, T.F., 1999. Dioxin contents in fly ash from large-scale MSW incinerators in Taiwan. Chemosphere 39, 2671-2680.

Chao, M.R., Wu, K.Y., Hu, C.W., Chang-Chien, G.P., Lee, W.J., Chang, L.W., 2003. Approaching gas-particle partitioning equilibrium of atmospheric PCDD/Fs with increasing distance from an incinerator: measurements and observations on modeling. Atmospheric Environment, Revised.

Coleman, P.J., Lee, R.G.M., Alcock, R.E., Jones, K.C., 1997. Observations on $\mathrm{PAH}, \mathrm{PCB}$, and $\mathrm{PCDD} / \mathrm{F}$ trends in $\mathrm{UK}$ urban air, 1991-1995. Environmental Science and Technology $31,2120-2124$.

Hu, C.W., Chao, M.R., Wu, K.Y., Chang-Chien, G.P., Lee, W.J., Chang, L.W., Lee, W.S., 2003. Characterization of multiple airborne particulate metals in the surroundings of a municipal waste incinerator in Taiwan. Atmospheric Environment 37, 2845-2852.

Kaupp, H., McLachlan, M.S., 1999. Atmospheric particle size distributions of polychlorinated dibenzo- $p$-dioxins and dibenzofurans (PCDD/Fs) and polycyclic aromatic hydrocarbons (PAHs) and their implications for wet and dry deposition. Atmospheric Environment 33, 85-95.

Kaupp, H., McLachlan, M.S., 2000. Distribution of polychlorinated dibenzo- $P$-dioxins and dibenzofurans (PCDD/ Fs) and polycyclic aromatic hydrocarbons (PAHs) within the full size range of atmospheric particles. Atmospheric Environment 34, 73-83.

Kaupp, H., Towara, J., McLachlan, M.S., 1994. Distribution of polychlorinated dibenzo- $P$-dioxins and dibenzofurans in atmospheric particulate matter with respect to particle-size. Atmospheric Environment 28, 585-593.
Kouimtzis, T., Samara, C., Voutsa, D., Balafoutis, C., Muller, L., 2002. PCDD/Fs and PCBs in airborne particulate matter of the greater Thessaloniki area, N. Greece. Chemosphere 47, 193-205.

Kurokawa, Y., Takahiko, M., Matayoshi, N., Satoshi, T., Kazumi, F., 1998. Distribution of polychlorinated dibenzo$p$-dioxins and dibenzofurans in various sizes of airborne particles. Chemosphere 37, 2161-2171.

Lee, R.G.M., Jones, K.C., 1999. Gas-particle partitioning of atmospheric PCDD/Fs: Measurements and observations on modeling. Environmental Science and Technology 33, 3596-3604.

Lee, R.G.M., Green, N.J.L., Lohmann, R., Jones, K.C., 1999. Seasonal, anthropogenic air mass, and meteorological influences on the atmospheric concentrations of polychlorinated dibenzo-p-dioxins and dibenzofurans (PCDD/Fs): Evidence for the importance of diffuse combustion sources. Environmental Science and Technology $33,2864-2871$.

Lee, W.J., Su, C.C., Sheu, H.L., Fan, Y.C., Chao, H.R., Fang, G.C., 1996. Monitoring and modeling of PCB dry deposition in urban area. Journal of Hazardous Materials 49, 57-88.

Lohman, K., Seigneur, C., 2001. Atmospheric fate and transport of dioxins: local impacts. Chemosphere 45, 161-171.

Lohmann, R., Jones, K.C., 1998. Dioxins and furans in air and deposition: A review of levels, behaviour and processes. Science of the Total Environment 219, 53-81.

Lohmann, R., Green, N.J.L., Jones, K.C., 1999. Detailed studies of the factors controlling atmospheric $\mathrm{PCDD} / \mathrm{F}$ concentrations. Environmental Science and Technology 33, $4440-4447$.

Lohmann, R., Harner, T., Thomas, G.O., Jones, K.C., 2000 a. A comparative study of the gas-particle partitioning of PCDD/Fs, PCBs, and PAHs. Environmental Science and Technology 34, 4943-4951.

Lohmann, R., Lee, R.G.M., Green, N.J.L., Jones, K.C., 2000 b. Gas-particle partitioning of PCDD/Fs in daily air samples. Atmospheric Environment 34, 2529-2537.

Lorber, M., Pinsky, P., Gehring, P., Braverman, C., Winters, D., Sovocool, W., 1998. Relationships between dioxins in soil, air, ash, and emissions from a municipal solid waste incinerator emitting large amounts of dioxins. Chemosphere 37, 2173-2197.

Ma, H.W., Lai, Y.L., Chan, C.C., 2002. Transfer of dioxin risk between nine major municipal waste incinerators in Taiwan. Environment International 28, 103-110.

Marple, V.A., Rubow, K.L., Behm, S.M., 1991. A microorifice uniform deposit impactor (MOUDI): description, calibration, and use. Aerosol Science and Technology 14, 434-446.

Mukerjee, D., 1998. Health impact of polychlorinated dibenzop-dioxins: a critical review. Journal of the Air and Waste Management Association 48, 157-165.

National research council (NRC), 2000. Understanding health effects of incineration. In: Waste Incineration and Public Health, National Academy, Washington, DC, pp. 140-155 (Chapter 5). 
Noll, K.E., Pontius, A., Frey, R., Gould, M., 1985. Comparison of atmospheric coarse particles at an urban and nonurban site. Atmospheric Environment 19, 1931-1944.

Noll, K.E., Fang, K.Y.P., Yuen, P.F., 1990. Atmospheric coarse particulate concentrations and dry deposition fluxes for ten metals in two urban environments. Atmospheric Environment 24, 903-909.

Oberdorster, G., Ferin, J., Lehnert, B.E., 1994. Correlation between particle-size, in-vivo particle persistence, and lung injury. Environmental Health Perspectives 102, 173-179.

Offenberg, J.H., Baker, J.E., 1999. Aerosol size distributions of polycyclic aromatic hydrocarbons in urban and over water atmospheres. Environmental Science and Technology 33, 3324-3331.

Ogura, I., Masunaga, S., Nakanishi, J., 2001. Congener-specific characterization of PCDDs/PCDFs in atmospheric deposition: comparison of profiles among deposition, source, and environmental sink. Chemosphere 45, 173-183.

Oh, J.E., Choi, J.S., Chang, Y.S., 2001. Gas/particle partitioning of polychlorinated dibenzo- $p$-dioxins and dibenzofurans in atmosphere; evaluation of predicting models. Atmospheric Environment 35, 4125-4134.

Oh, J.E., Chang, Y.S., Kim, E.J., Lee, D.W., 2002. Distribution of polychlorinated dibenzo-p-dioxins and dibenzofurans (PCDD/Fs) in different sizes of airborne particles. Atmospheric Environment 36, 5109-5117.
Schnelle-Kreis, J., Gebefugi, I., Welzl, G., Jaensch, T., Kettrup, A., 2001. Occurrence of particle-associated polycyclic aromatic compounds in ambient air of the city of Munich. Atmospheric Environment 35, S71-S81.

Sheu, H.L., Lee, W.J., Lin, S.J., Fang, G.C., Chang, H.C., You, W.C., 1997. Particle-bound PAH content in ambient air. Environmental Pollution 96, 369-382.

Valberg, P.A., Drivas, P.J., McCarthy, S., Watson, A.Y., 1996. Evaluating the health impacts of incinerator emissions. Journal of Hazardous Materials 47, 205-227.

Venkataraman, C., Thomas, S., Kulkarni, P., 1999. Size distributions of polycyclic aromatic hydrocarbons-gas/ particle partitioning to urban aerosols. Journal of Aerosol Science 30, 759-770.

Wang, L.C., Lee, W.J., Lee, W.S., Chang-Chien, G.P., Tsai, P.J., 2003a. Characterizing the emissions of polychlorinated dibenzo- $p$-dioxins and dibenzofurans from crematories and their impacts to the surrounding environment. Environmental Science and Technology 37, 62-67.

Wang, L.C., Lee, W.J., Lee, W.S., Chang-Chien, G.P., Tsai, P.J., 2003b. Effect of chlorine content in feeding wastes of incineration on the emission of polychlorinated dibenzo- $p$ dioxins/dibenzofurans. Science of the Total Environment 302, 185-198. 